\title{
Hierarchical Cluster Analysis of Brassica juncea L. Genotypes Using Morphological Traits
}

\author{
Subha Lakshmi Saikia ${ }^{1}$, Gyanendra Kumar Rai ${ }^{{ }^{*}}$, R.K. Salgotra1, \\ S.K. Rai ${ }^{2}$, Monika Singh ${ }^{3}$ and P.K. Rai ${ }^{4}$ \\ ${ }^{1}$ School of Biotechnology, SKUAST-Jammu180009 (J\&K), India \\ ${ }^{2}$ Division of PBG, SKUAST-Jammu180009 (J\&K), India \\ ${ }^{3}$ G.L. Bajaj IT and Management, Greater Noida, GB Nagar, UP - 201306, India \\ ${ }^{4}$ ACHR, Udheywala, SKUAST-Jammu 180009 (J\&K), India \\ *Corresponding author
}

\begin{tabular}{|c|c|}
\hline & A B \\
\hline & \multirow{7}{*}{$\begin{array}{l}\text { Significant variations were noted in } 15 \text { Brassica juncea L. genotypes in respect of } \\
\text { morphological characters. The plant height, number of primary branches and number of } \\
\text { secondary branches varied from } 114.33 \mathrm{~cm} \text { to } 198.00 \mathrm{~cm}, 3.67 \text { to } 8.00 \text { and } 11.00 \text { to } 16.00 \text {, } \\
\text { respectively. The number of siliqua per plant and number of seeds per siliqua ranged from } \\
501.00 \text { to } 692.67 \text { and } 14.67 \text { to } 18.00 \text { were noted among the genotypes, respectively, } \\
\text { Maximum number of siliqua per plant and number of seeds per siliqua were recorded in } \\
\text { Pusa Bold and RB-50, respectively. Number of siliqua in main raceme ranged from } 36.00 \\
\text { to } 57.33 \text {. SKJM-5 showed maximum number of siliqua in main raceme ( } 57.33 \text { ) and } \\
\text { minimum was recorded in PM } 21 \text { ( } 36.00) \text {. } 1000 \text { seed test weight for the various Brassica } \\
\text { juncea L. genotypes ranged from } 3.67 \mathrm{gm} \text { to } 5.08 \text { gm. Maximum and minimum } 1000 \text { seed } \\
\text { test weight was recorded in Pusa Karishma and PusaMahak, respectively. In cluster } \\
\text { analysis, genotypes were mainly divided at the first node into } 2 \text { clusters with } 10 \text { (Cluster I) } \\
\text { and } 5 \text { (Cluster II) genotypes in different groups. Cluster with } 10 \text { genotypes was again } \\
\text { divided into } 2 \text { groups with } 5 \text { genotypes in each group. Cluster with } 5 \text { genotypes was again } \\
\text { divided into } 2 \text { groups with } 3 \text { and } 2 \text { genotypes, respectively. Hence hybridization involving } \\
\text { the inter cluster representatives of cluster would be more useful in chilly breeding } \\
\text { programme. }\end{array}$} \\
\hline Keywo & \\
\hline & \\
\hline & \\
\hline Ar & \\
\hline & \\
\hline & \\
\hline
\end{tabular}

\section{Introduction}

Indian mustard is the third important oilseed crop in the world after soyabean (Glycine max) and palm (Elaeisguineensis Jacq.) oil. These are major oilseed and vegetable crops that are grown worldwide barring the tropics. The oil content in Indian mustard seed varies from $30 \%$ to $48 \%$. Indian mustard occupies more than $80 \%$ of the total rapeseed mustard cultivated area, contributes nearly $27 \%$ of edible oil pool in India, and accounts for $>13 \%$ of the global edible oil production (Meena et al., 2014). In India, it is the second most important edible oilseed after soyabean (Sutariya et al., 2011). India contributes 
$28.3 \%$ and $19.8 \%$ in world acreage and production. India produces around 6.7 million tonnes of rapeseed-mustard next to China (1112 million tonnes) and European Union (10-13 million tonnes) (Shekhawat et al., 2012). Brassica oilseed crop have become the world's third largest source of edible vegetable oils. Indian mustard (Brassica juncea) is grown for oil-seed usage in India mainly and presently gaining importance in Canada and USA as an alternative to rapeseed i.e. Brassica napus (Kumar et al., 2015). In general, genetic improvement of crops can be accelerated when broad genetic diversity and the information of these genetic resources are available. At the same time it is necessary to develop better methods of characterization and evaluation of germplasm collections, to improve strategies for conservation and collection of germplasm and to increase the utilization of plant genetic resources. A successful crop improvement program depends upon the genetic diversity of a crop for achieving the goals of producing high yielding and resistant varieties (Padulosi, 1993). Genetic study based on the multivariate analysis is a powerful tool for determining the degree of divergence between populations, the relative contribution of different components to the total divergence and the nature of forces operating at different levels (Ceolin et al., 2007; Singh et al., 2007). Hence, the present study was undertaken to study the nature and magnitude of genetic divergence, to identify characters which contribute maximum to genetic diversity and to identify suitable genotypes for use in breeding programme for broadening the genetic base in Brassica juncea $\mathrm{L}$.

\section{Materials and Methods}

Fifteen genotypes of Indian mustard seeds were sown during rabi season of 2015-16 and 2016-17 in a Randomized Block Design (RBD) with 3 replications at the experimental field of School of Biotechnology, Sher-e-
Kashmir University of Agricultural Sciences and Technology- Jammu. Field observation were recorded for plant height, number of primary branches, number of secondary branches, number of seeds per siliqua, number of siliqua per plant, number of siliqua in main raceme and 1000 seed test weight. Five competitive plants were randomly selected from the central row of each plot in each replication to record observations on the quantitative traits. The statistical analysis was done on the mean basis across the genotypes. The differences between the lines were tested using one-way analysis of variance (ANOVA) and DMR-test was used to determine the significant differences among the test materials. Differences were considered to be significant at $\mathrm{p} \leq 0.05$. The data on the all characters were computed and agglomerative hierarchical clustering was done using SPSS version 10.1 software (Rai et al., 2010). The clustering was based on the squared Euclidean distance and the average linkage between groups was taken as the average of the distance between all pairs of cases with one member of each group (Kalloo et al., 2005).

\section{Results and Discussion}

\section{Morphological traits}

Fifteen Brassica juncea L. genotypes were characterized morphologically in the present study by comparing plant height, number of primary branches, number of secondary branches, number of seeds per siliqua, number of siliqua per plant, number of siliqua in main raceme and 1000 seed test weight (Table 1).

The plant height data revealed significant variation among the Brassica juncea $\mathrm{L}$. genotypes (LSD $(p \leq 0.05) \quad 6.01)$. The plant height ranged from 114.33 to $198.00 \mathrm{~cm}$. The maximum plant height was recorded in PM 21 $(198.00 \mathrm{~cm})$ followed by SKJM-5 $(190.00 \mathrm{~cm})$, PM-24 (188.00cm), Pusa Karishma $(187.33 \mathrm{~cm})$, RSPR-03 $(187.33 \mathrm{~cm})$, Varuna 
(183.00 cm), RL-1359 (182.67 cm), RSPR-01 $(182.00 \mathrm{~cm})$, Pusa Bold $(179.67 \mathrm{~cm})$, RB-50 $(178.00 \mathrm{~cm})$, Kranti $(171.33 \mathrm{~cm})$, NRCDR-2 $(168.67 \mathrm{~cm})$, Pusa Mahak $(166.00 \mathrm{~cm})$ and NPJ $-112 \quad(159.67 \mathrm{~cm})$ and minimum was recorded in Pusa Tarak $(114.33 \mathrm{~cm})$. The genotypes RSPR-01, RSPR-03, Pusa Karishma, Varuna, RL-1359 and PM-21 was observed as statistically at par. The number of primary branches ranged from 3.67 to 8.00 amongst the 15 Brassica juncea L. genotypes. The maximum number of primary branches was recorded in Kranti (8.00) followed by RB50 (6.33), Pusa Tarak (6.33), SKJM-5 (6.00), NRCDR-2 (6.00), PM-24 (6.00) and RL-1359 (6.00), RSPR-01 (6.00), RSPR-03 (6.00), NPJ-112 (5.33), Pusa Mahak (5.33), Pusa Karishma (5.33), PM-21 (4.33) and Pusa Bold (4.00). Whereas, minimum number of primary branches was noted in Varuna (3.67). The genotypes RSPR-01, RSPR-03, Pusa Karishma, PM-21 and Pusa Bold, RL-1359, PM-24, Pusa Mahak, NPJ-112, NRCDR-2 and SKJM-5 are statistically at par. Brassica juncea $\mathrm{L}$. genotypes data revealed significant variation in respect of number of secondary branches (LSD $(p \leq 0.05) 2.39)$. The number of secondary branches varied from 11.00 to 16.00. SKJM- 5 genotypes showed maximum number of secondary branches (16.00) followed by NRCDR-2 (15.33), Kranti (14.67), RB-50 (14.00), PM-24 (14.00), RSPR-03 (14.00), RL-1359 (13.67), Pusa Tarak (13.00), Pusa Bold (13.00), RSPR-01 (13.00), Varuna (12.67), Pusa Karishma (12.67), Pusa Mahak (12.00) and NPJ-112 (11.33). However, minimum number of secondary branches were noted in PM-21 (11.00). The genotypes RSPR-01, RSPR-03, Pusa Karishma, Pusa Bold, Varuna, Kranti, RL-1359, Pusa Tarak, PM-24, RB-50, Pusa Mahak, NPJ-112, NRCDR-2 and SKJM-5 are significantly at par. Number of siliqua per plant data revealed significant variation among the Brassica juncea L. genotypes (LSD $(p \leq 0.05) 15.97)$. The number of siliqua per plant varied from 501.00 to 692.67. The maximum number of siliqua per plant was recorded in Pusa Bold (692.67) followed by Kranti (691.33), RB-50 (689.67), Varuna (689.67), RSPR-03 (687.00), NPJ-112 (686.67), Pusa Karishma (686.00), NRCDR-2 (684.67), PM-21 (684.33), RSPR-01 (664.33), Pusa Tarak (553.00), RL-1359 (549.33), Pusa Mahak (524.00) and SKJM-5 (511.00) whereas minimum was recorded in PM-24 (501.00). Significant (LSD $(p \leq 0.05) \quad 3.23)$ variation were observed in respect of number of seeds per siliqua among the genotypes. The number of seeds per siliqua varied from 14.67 to 18.00 among the 15 Brassica juncea $\mathrm{L}$. genotypes. The maximum number of seeds per siliqua was recorded in RB-50 (18.00), followed by Pusa Tarak (17.67), RB-50 (17.00), NPJ-112 (17.00), Pusa Mahak (17.00), PM-24 (17.00), RL-1359 (17.00), Pusa Karishma (17.00), RSPR-01 (16.00), SKJM-5 (15.67), NRCDR 2 (15.67), Kranti (15.67) and Pusa Bold (15.00). Whereas, minimum number of seeds per siliqua (14.67) was recorded in three genotypes i.e. Varuna, PM-21 and RSPR-03. Number of siliqua on the main shoot is a major yield contributing trait. The number of siliqua in main raceme data revealed significant variation among the Brassica juncea genotypes [LSD $(\mathrm{p} \leq 0.05)$ 7.40]. The number of siliqua in main raceme ranged from 36.00 to 57.33 . The maximum number of siliqua in main raceme was recorded in SKJM-5 (57.33) followed by PM24 (54.00), RL-1359 (52.67), RB -50 (52.33), NRCDR-2 (52.00), Pusa Tarak (50.33), NPJ112 (49.33), Pusa Mahak (48.67), Varuna (48.00), Pusa Bold (46.00), Kranti (44.00), Pusa Karishma (40.67), RSPR-01 (38.33) and RSPR-03 (37.67) however, minimum was recorded in PM-21 (36.00). The genotypes RSPR-01, Pusa Karishma, Pusa Bold, Varuna, Kranti, RL -1359, Pusa Tarak, PM-24, RB-50, Pusa Mahak, NPJ -112 and NRCDR- 2 are significantly at par. The data for 1000 seed test weight revealed significant variation 
among the Brassica juncea L. genotypes (LSD $(\mathrm{p} \leq 0.05) 0.23) .1000$ seed test weight for the various Brassica juncea $L$. genotypes ranged from $3.67 \mathrm{gm}$ to $5.08 \mathrm{gm}$. The maximum test weight (1000seeds) was recorded in Pusa Karishma (5.08 gm) followed by NRCDR-2 (4.85 gm), Kranti (4.85 gm), RB-50 (4.65), Pusa Bold (4.60 gm), Varuna (4.57), SKJM- 5 (4.41), NPJ-112 (4.36), PM-21 (4.31), PM-24 (4.26), RSPR-01 (4.25), RSPR 03 (4.24), RL1359 (4.23) and Pusa Tarak (3.74) whereas minimum was recorded in Pusa Mahak (3.67). The genotypes Pusa Bold, Varuna, Kranti, RB-50, NPJ-112, NRCDR-2 and SKJM-5 are statistically at par. The morphological traits observations were agreement with the findings reported by Renuka et al., (2017). Vinu et al., (2013) also reported significant genetic variations for the 12 yield and yield contributing traits including plant height, days to maturity, point to first branch, number of siliquae on main shoot, number of primary branches, number of secondary branches, main shoot length, point to first siliquae, siliqua length, number of seeds per siliquae, seed yield per plant and 1000 seed weight. Similar results were also been reported by Rai et al., (2017), Vaishnava et al., (2006), Alie et al., (2009), Singh et al., (2010), Yadava et al., (2009) and Chaudhary and Rai (2013) on metric traits in Brassica juncea.
Hierarchical cluster analysis of Brassica juncea $L$. genotypes

Hierarchical cluster analysis was conducted on different morphological characters. Distance between all pairs of genotypes was calculated using squared Euclidean distance method and genotypes were clustered based on ward's method. Cluster analysis showed four clusters (Figure1). From the dendogram, it can be concluded that the genotypes were mainly divided at the first node into 2 clusters with 10 (Cluster I) and 5 (Cluster II) genotypes in different groups. Cluster with 10 genotypes was again divided into 2 groups with 5 genotypes in each group. Cluster with 5 genotypes was again divided into 2 groups with 3 and 2 genotypes, respectively. The results agreement with the findings of Rai et al., (2010). Similar findings were also reported by Kalloo et al., (2005) in Pisum sativum L. and Singh et al., (2007) in tomato. Since these cluster are group of individuals possessing similar characters mathematically gathered into the same clusters, these individuals are supposed to exhibit higher external heterogeneity. Hence hybridization involving the inter cluster representatives of cluster would be more useful in chilly breeding programme.

Figure.1 Hierarchical clustering of Brassica juncea L. genotypes based on Morphological traits

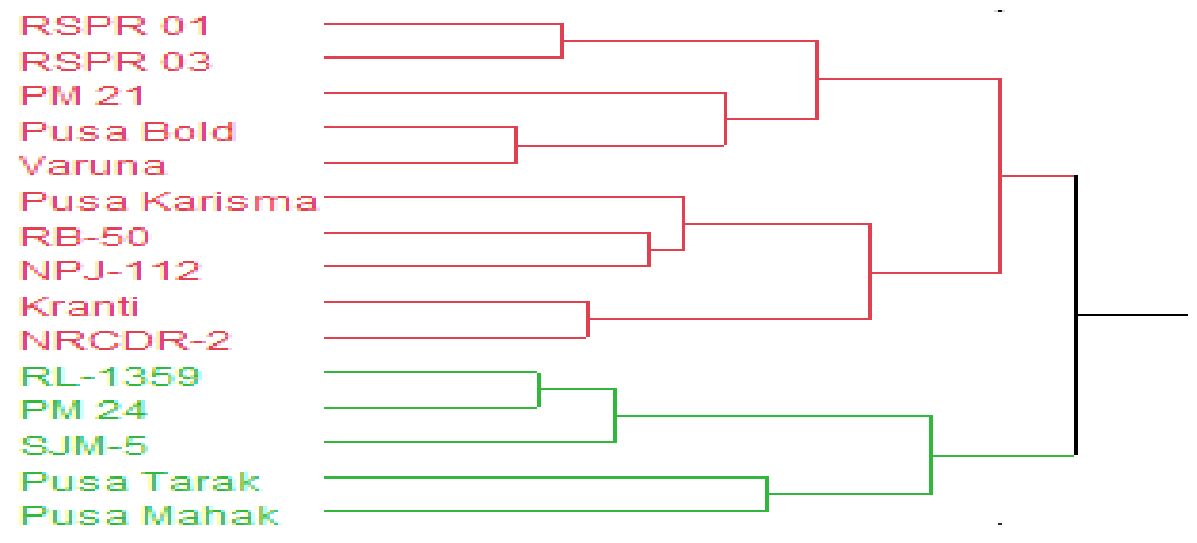


Table.1 Morphological and yield attributing traits in Brassica juncea L. Genotypes

\begin{tabular}{|c|c|c|c|c|c|c|c|c|}
\hline S.No. & Genotypes & $\begin{array}{l}\text { Plant height } \\
(\mathrm{cm})\end{array}$ & $\begin{array}{l}\text { No. of } \\
\text { primary } \\
\text { branches }\end{array}$ & $\begin{array}{c}\text { No. of } \\
\text { secondary } \\
\text { branches }\end{array}$ & $\begin{array}{l}\text { No. of seeds } \\
\text { per siliqua }\end{array}$ & $\begin{array}{l}\text { No. of siliqua } \\
\text { per plant }\end{array}$ & $\begin{array}{l}\text { No. of siliqua } \\
\text { in main } \\
\text { raceme }\end{array}$ & $\begin{array}{c}1000 \text { seed } \\
\text { test } \\
\text { weight }(\mathrm{gm})\end{array}$ \\
\hline 1. & RSPR-01 & $182.00^{\mathrm{cd}}$ & $6.00^{\mathrm{bc}}$ & $13.00^{\text {bcde }}$ & $16.00^{\mathrm{a}}$ & $664.33^{b}$ & $38.33^{\mathrm{e}}$ & $4.25^{\mathrm{e}}$ \\
\hline 2. & RSPR-03 & $187.33^{b c}$ & $6.00^{b c}$ & $14.00^{\mathrm{abcd}}$ & $14.67^{\mathrm{a}}$ & $687.00^{\mathrm{a}}$ & $37.67^{\mathrm{ef}}$ & $4.24^{\mathrm{e}}$ \\
\hline 3. & Pusa Karishma & $187.33^{b c}$ & $5.33^{\text {bcd }}$ & $12.67^{\text {bcde }}$ & $17.00^{\mathrm{a}}$ & $686.00^{\mathrm{a}}$ & $40.67^{\text {def }}$ & $5.08^{\mathrm{a}}$ \\
\hline 4. & PM-21 & $198.00^{\mathrm{a}}$ & $4.33^{\mathrm{cde}}$ & $11.00^{\mathrm{e}}$ & $14.67^{\mathrm{a}}$ & $684.33^{a}$ & $36.00^{f}$ & $4.31^{\mathrm{e}}$ \\
\hline 5. & Pusa Bold & $179.66^{d}$ & $4.00^{\mathrm{de}}$ & $13.00^{\text {bcde }}$ & $15.00^{\mathrm{a}}$ & $692.67^{\mathrm{a}}$ & $46.00^{\text {bcde }}$ & $4.60^{\mathrm{bcd}}$ \\
\hline 6. & Varuna & $183.00^{\mathrm{cd}}$ & $3.67^{\mathrm{e}}$ & $12.67^{\text {bcde }}$ & $14.67^{\mathrm{a}}$ & $689.67^{\mathrm{a}}$ & $48.00^{\mathrm{bcd}}$ & $4.57^{\mathrm{cd}}$ \\
\hline 7. & Kranti & $171.33^{\mathrm{f}}$ & $8.00^{\mathrm{a}}$ & $14.67^{\mathrm{ebc}}$ & $15.67^{\mathrm{a}}$ & $691.33^{\mathrm{a}}$ & $44.00^{\text {cdef }}$ & $4.85^{\mathrm{ab}}$ \\
\hline 8. & RL-1359 & $182.66^{\mathrm{cd}}$ & $6.00^{b c}$ & $13.67^{\text {ebcde }}$ & $17.00^{\mathrm{a}}$ & $549.33^{c}$ & $52.67^{\mathrm{ab}}$ & $4.23^{\mathrm{e}}$ \\
\hline 9. & Pusa Tarak & $114.33^{\mathrm{g}}$ & $6.33^{b}$ & $13.00^{\text {bcde }}$ & $17.67^{\mathrm{a}}$ & $553.00^{\mathrm{c}}$ & $50.33^{a b c}$ & $3.74^{\mathrm{f}}$ \\
\hline 10. & PM-24 & $188.00^{\mathrm{bc}}$ & $6.00^{b c}$ & $14.00^{\mathrm{ebcd}}$ & $17.00^{\mathrm{a}}$ & $501.00^{\mathrm{e}}$ & $54.00^{\mathrm{ab}}$ & $4.26^{\mathrm{e}}$ \\
\hline 11. & $\mathrm{RB}-50$ & $178.00^{d}$ & $6.33^{b}$ & $14.00^{\mathrm{ebcd}}$ & $18.00^{a}$ & $689.67^{a}$ & $52.33^{a b c}$ & $4.65^{b c}$ \\
\hline 12. & Pusa Mahak & $166.00^{e}$ & $5.33^{\mathrm{bcd}}$ & $12.00^{\text {cde }}$ & $17.00^{\mathrm{a}}$ & $524.00^{d}$ & $48.67^{\mathrm{bcd}}$ & $3.67^{\mathrm{f}}$ \\
\hline 13. & NPJ-112 & $159.66^{f}$ & $5.33^{\mathrm{bcd}}$ & $11.33^{\mathrm{de}}$ & $17.00^{\mathrm{a}}$ & $686.67^{a}$ & $49.33^{a b c}$ & $4.36^{\mathrm{des}}$ \\
\hline 14. & NRCDR-2 & $168.66^{\mathrm{e}}$ & $6.00^{b c}$ & $15.33^{\mathrm{eb}}$ & $15.67^{\mathrm{a}}$ & $684.67^{a}$ & $52.00^{a b c}$ & $4.85^{a b}$ \\
\hline 15. & SKJM-5 & $190.00^{b}$ & $6.00^{b c}$ & $16.00^{e}$ & $15.67^{\mathrm{a}}$ & $511.00^{\text {de }}$ & $57.33^{a}$ & $4.41^{\mathrm{cde}}$ \\
\hline & Range & $114.33-198.00$ & $3.67-8.00$ & $11-16$ & 14.67-18.00 & $501.00-692.67$ & $36.00-57.33$ & $3.67-5.08$ \\
\hline & LSD (0.05) & 6.01 & 1.43 & 2.39 & 3.23 & 15.97 & 7.40 & 0.23 \\
\hline
\end{tabular}




\section{References}

Alie F.A., Singh T., Tariq and Sharma P. K. 2009. Genetic diversity analysis in Indian mustard [Brassica juncea (1.) czern\&coss]. Progressive AgricultureAn International Journal. 9: 50-53.

Choudhary R. and Rai G.K. 2013. Assesment of genetic diversity in Brassica species using biochemical markers. M.Sc. Thesis submitted at SKUAST-Jammu.

Devi R., Devshini N., Vivekananda Y. and Sharma Ph. R. 2017. Genetic diversity analysis in Indian mustard (Brassica juncea L. Czern and Coss) genotypes using agro-morphological parameters. Electronic Journal of Plant Breeding. 8(3): 749-753.

Kalloo G., Rai M., Singh J., Verma A., Kumar R., Rai G.K. and Vishwanath. 2005. Morphological and biochemical variability in pea (Pisum sativum L.). Vegetable Science. 32: 19-23.

Kumar Pradeep, Yadav R.K. and Singh L. 2015. Corelation analysis and study of genetic parameters for different attributes in Indian mustard (Brassica juncea L. Czern \& Coss). Environment and Ecology. 33(3A):1401-1406.

Meena H.S., Ram B., Kumar A., Singh B.K., Meena P.D., Singh V.V. and Singh D. 2014. Heterobeltiosis and standard heterosis for seed yield and important traits in Brassica juncea. Journal of Oilseed Brassica. 5(2):134-140.

Padulosi S. 1993. Genetic diversity, taxonomy and ecogeographical survey of the wild relatives of cowpea (Vigna unguiculata(L.) Walp). Ph. D. Thesis, University of Lagos, Nigeria.

Rai S.K., Sandhu Rubby, Jat Lekhraj, Kumar A., Kiran U., Mukhtar S., Kohli S. and Rai. G.K. 2017.Study of Heterosis and Combining Ability for Yield and its Component Traits in Brassica juncea $L$. International Journal of Current
Microbiology and Applied Sciences.6(12): 2570-2579.

Rai S.K., Rai, G.K. and Singh, A.K. 2010. Hierarchical cluster analysis in exotic introductions of chilli (Capsicum annuum L.). Environment and Ecology. 28(4A): 2423-2425.

Shekhawat K., Rathore S. S., Premi O. P., Kandpal B. K. and Chauhan J. S. 2012. Advances in agronomic management of Indian mustard (Brassica juncea (L.) Czernj. Cosson): an overview. International Journal of Agronomy. 14 pages.

Singh D., Arya R. K., Chandra N., Niwas R. and Salisbury P. 2010. Genetic diversity studies in relation to seed yield and its component traits in Indian mustard (Brassica juncea L. Czern \& Coss.). Journal of Oilseeds Brassica. 1: 19-22.

Singh J., Rai M., Kumar R., Prasanna H.C., Verma A. and Rai, G.K.2007. Genotypic Variation and Hierarchical Clustering of Tomato (Solanum lycopercicum) based on Morphological and Biochemical traits. Vegetable Science. 34(1): 40-45.

Sutariya D.A., Patel K.M., Bhadauria H.S., Vaghela P.O., Prajapati D.B. and Parmar, S.K. 2011. Genetic diversity for quality traits in Indian mustard (Brassica juncea L.). Journal of Oilseed Brassica. 2(1): 44-47.

Vaishnava A., Sachan J.N. and Tewari S.K. 2006. Genetic divergence for important quantitative traits in Indian mustard (Brassica juncea (L.) Czern and Coss). Agricultural Science Digest.26: 269272.

Vinu V., Singh N., Vasudev S., Yadav D. K., Kumar S., Naresh S. Bhat S. R. and Prabhu K.V. 2013. Assessment of genetic diversity in Brassica juncea (Brassicaceae) genotypes using phenotypic differences and SSR markers. Int. J. Trop. Biol. 61(4): 1919- 
1934.

Yadava D.K., Sapra R.L., Sujata V., Dass B. and Prabhu K.V. 2009. Selection of high diversity with a minimal set of accessions from Indian mustard \{Brassica juncea (L.) Czern \& Coss. germplasm collection. Indian Journal of Agricultural Sciences. 79:552-554.

\section{How to cite this article:}

Subha Lakshmi Saikia, Gyanendra Kumar Rai, R.K. Salgotra, S.K. Rai, Monika Singh and Rai, P.K. 2018. Hierarchical Cluster Analysis of Brassica juncea L. Genotypes Using Morphological Traits. Int.J.Curr.Microbiol.App.Sci. 7(12): 690-696.

doi: https://doi.org/10.20546/ijcmas.2018.712.085 